DOI: https://doi.org/10.24867/14CG06Ninkovic

\title{
IZBOR OPTIMALNOG DINAMIČKOG PLANA ZA IZGRADNJU HOTELSKOG KOMPLEKSA
}

\section{SELECTION OF THE OPTIMAL DYNAMIC PLAN FOR A HOTEL COMPLEX CONSTRUCTION}

\author{
Srđan Ninković, Fakultet tehničkih nauka, Novi Sad
}

\section{Oblast - GRAĐEVINARSTVO}

Kratak sadržaj - U radu su analizirani dinamički planovi varijantnih rešenja izgradnje hotelsko - turističkog kompleksa "Fruške terme" u Vrdniku. Prikazan je i postupak izbora optimalnog varijantnog rešenja metodama višekriterijumske optimizacije.

Ključne reči: Izvođenje, Dinamički plan, Optimizacija

Abstract - This paper analyses dynamic plans of variant solutions for tourist hotel complex construction of "Fruške Terme" in Vrdnik. Also, presented here is the procedure of choosing the optimal variant solution by multicriteria optimization methods.

Keywords: Performance, Dynamic planning, Optimization

\section{UVOD}

Predmet ovog rada je sagledavanje mogućnosti načina izgradnje jednog složenog hotelskog kompleksa, praćenje dinamike pojedinih grupa radova za različite objekte unutar celine i njihova međusobna usklađenost u zavisnosti od izabrane jedne od obrađene četiri varijante organizaciono-tehnoloških rešenja koje su u razmatrane daljem tekstu.

Analiza dinamičkih planova varijantnih rešenja izgradnje hotelskog kompleksa ima za cilj razmatranje prednosti i mana određenog pristupa izgradnji, uzimajući u obzir rokove, troškove, broj potrebnih izvršilaca tokom gradnje i dr.

Izbor optimalnih rešenja u složenim dinamičkim sistemima predstavlja veliki izazov s obzirom na svu nepredvidivost i velike rizike koje nosi sa sobom, s toga se radi olakšanja donošenja odluka i smanjenja rizika primenjuje niz naučnih metoda.

U ovom projektu korišćene su sledeće metode:

- tehnika mrežnog planiranja,

- metoda gantograma,

- višekriterijumska optimizacija (metode kompromisnog programiranja i višekriterijumsko rangiranje alternativnih rešenja).

\section{NAPOMENA:}

Ovaj rad proistekao je iz master rada čiji mentor je bio dr Milan Trivunić, red. prof.

\section{OPIS OBJEKTA I USLOVA GRAĐENJA}

HOTELSKO - TURISTIČKI KOMPLEKS '’FRUŠKE TERME" u Vrdniku.

Spratnost $4 \mathrm{Sut}+\mathrm{Pr}+3+\mathrm{Pk}$. (suteren $1+$ suteren $2+$ suteren 3 + suteren $4+$ prizemlje +3 sprata + potkrovlje $(\mathrm{Pk} 1 \mathrm{i}$ Pk2)) na katastarskoj parceli broj 2552/8 K.O.

Ukupna BRGP nadzemno iznosi $\mathrm{P}=12.886,27 \mathrm{~m} 2$; ukupna bruto izgrađena površina (podzemno i nadzemno) iznosi $\mathrm{P}=32.527,97 \mathrm{~m} 2$; ukupna neto površina objekta iznosi $\mathrm{P}=29.932,24 \mathrm{~m} 2$. Površina zemljišta pod objektom (sa nadstrešnicom kod glavnog ulaza) iznosi $\mathrm{P}=7.886,0$ $\mathrm{m} 2$.

Slika 1. Šema objekata u sklopu kompleksa

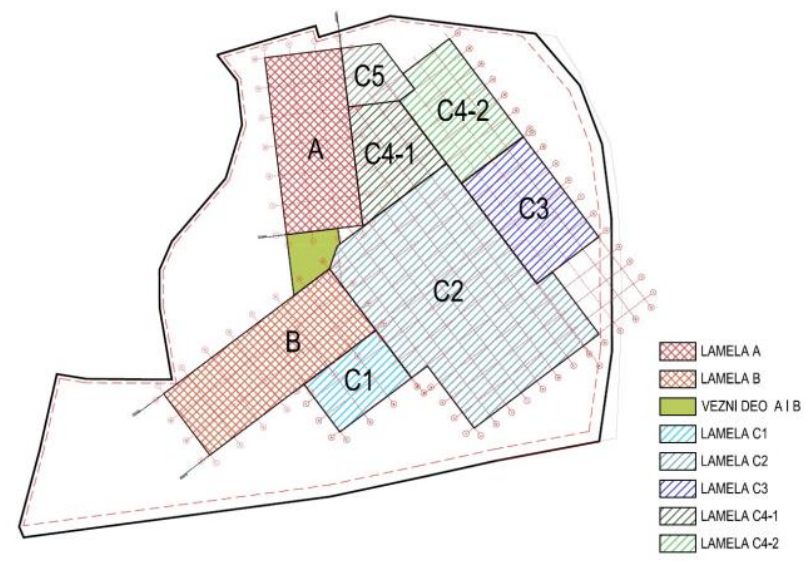

Za osnovni konstruktivni sistem je usvojen skeletni armirano betonski sistem.

Kompleks sačinjava više celina - objekata, različite spratnosti, funkcije, oblika i gabarita, koji su međusobno funkcionalno povezani.

Susedni objekti zbog velikih razlika u kotama suterenskih delova, nisu fundirani na istoj koti, što je osnovni postulat fundiranja. Ovo je opet posledica pada terena i položaja objekata na padini.

Objekat "A" i objekat "B", sa spavaćim blokom - sobama za smeštaj gostiju su formirani kao dva glavna višespratna, nezavisna objekta. Oni su postavljeni pod uglom jedan prema drugom, a funkcionalno su spojeni veznimstepenišnim delom. Sa pratećim sadržajima bloka "C" su povezani i čine jedinstvenu funkcionalnu celinu. Položajno deo "C" je lociran ispred ova oba objekta $\mathrm{i}$ on je formiran kao niska arhitektonska celina sa bazenima, a kaskadno postavljen, tako da je uklopljen u pad terena, $\mathrm{tj}$. prati teren. 


\section{ANALIZA DINAMIČKIH PLANOVA VARIJANTNIH REŠENJA IZVOĐENJA HOTELSKOG KOMPLEKSA}

Varijantna rešenja koja su u daljem tekstu razmatrana služe za sagledavanje globalne/grube dinamike, potrebnog vremena izvođenja radova kao i uzajamnih veza pojedinih grupa radova kako bi se stvorila slika o realnim mogućnostima roka izvedbe kao i pristupu gradnji ovog složenog kompleksa a sve zbog zadatih kratkih rokova. U grubu analizu su uvrštene sledeće grupe radova: iskopi/osiguranja temeljnih jama; armirano-betonski radovi; zidarski radovi; pokrivački radovi i suvomontažni radovi.

$\mathrm{Za}$ sve varijante koje su obrađene radovi počinju 04.06.2018. godine što je bilo vreme kada su radovi u stvarnosti zaista i otpočeli. Pored ostalog u varijantama je razmotren zimski period zbog radova na otvorenom kao i zahtevi investitora da hotelski kompleks bude otvoren $\mathrm{u}$ avgustu 2019. godine i da kompletna konstrukcija bazenskog dela bude gotova do sredine novembra 2018. godine zbog montaže inoksnih bazena koji su stizali iz inostranstva.

\subsection{Varijantno rešenje 1}

Početak analiziranih aktivnosti 04.06.2018. godine; završetak 25.05.2019. godine.

Ovo varijantno rešenje je bilo predviđeno projektom, kao i detaljnom razradom plana iskopa koje ga uslovljava, kao optimalno $\mathrm{u}$ datom trenutku a prihvaćeno $\mathrm{i}$ od strane izvođača radova pod rokovima koji su bili zadati ali koje je zato podrazumevalo izrazito dobru organizaciju rada jer nije bilo mnogo prostora za vremenska odstupanja aktivnosti od isplaniranog okvira.

Podrazumeva izgradnju kompleksa od najniže etaže '-4' (od najniže tačke ka najvišoj), objekti 'C1' i 'C2', što je i jedan od osnovnih postulata izgradnje posebno na ovakvom vidu terena u planinskom predelu, usecanje $u$ kosinu padine. Sa stanovišta izgradnje AB konstrukcije, kao i sa stanovišta bezbednosti na radu ovaj vid izgradnje je najracionalniji.

Preliminarna dinamika grubih radova pokazala je da se kompleks može završiti do zahtevanog roka, ali nije uzimala u obzir nepredviđene okolnosti do kojih je došlo kasnije $\mathrm{u}$ toku izgradnje. Naime, u geomehaničkom elaboratu naznačeno je da su istraživanja pokazala da nivo podzemne vode neće predstavljati problem za izradu objekata s obzirom da je niži od kote potrebnog iskopa za temelje kao i da je sastav zemlje takav da je mala verovatnoća pojave klizišta, što nije bio slučaj ni za jednu od dve stavke. Pojava klizišta i pored predloženog nagiba kosina škarpi a i nakon dodatnog obaranja nagiba bila je neminovna.

Pored toga, vremenski uslovi u leto 2018. godine prilikom iskopa bili su jako nepovoljni u smislu konstantnih kiša koje su onemogućavale iskop, posebno na ovako glinovitom tlu i na površini kompleksa te veličine gde kamioni za odvoz zemlje nisu mogli prilaziti.

Prethodno pomenuto imalo je za posledicu da su se radovi na samoj izradi AB konstrukcije drastično prolongirali, čime i samo temeljenje svih pojedinih objekata nije bilo završeno do zime koja je takođe donela nove izazove i produžila vreme izvođenja.

Jedan od zahteva investitora bio je i rok za završetak objekata u bazenskom delu jer su sami inoksni bazeni stizali iz inostranstva kao i stručni kadar, što je predstavljalo značajnu novčanu stavku u celokupnoj finanskijskoj strukturi i nije bilo previše mogućnosti za odstupanje. Sa tog stanovišta i pored odstupanja $u$ izgradnji ostalih delova kompleksa pre svega smeštajnih kapaciteta, ovaj bazenski deo je izgrađen u roku (sredina novembra 2018. godine), s obzirom da je i podrazumevao potrebu za izgradnjom prvo najnižih delova kompleksa, što je svakako bilo uslovljeno ovim pristupom gradnje.

\subsection{Varijantno rešenje 2}

Početak analiziranih aktivnosti 04.06.2018. godine; završetak 16.03.2019. godine.

Varijanta 2 podrazumeva primarno izgradnju hotelskosmeštajnog kapaciteta s obzirom da je on najzahtevniji po pitanju potrebnog vremena za izradu svih etaža kao i završnih radova koji ih prate.

Dinamički plan ove varijante pokazao je da je za njen završetak potrebno najmanje od ostalih varijanti, 286 kalendarskih dana što je jedan od bitnijih faktora za zadate uslove.

Ovim planom se odmah nakon iskopa zemlje za podzemni deo '-2' kreće sa temeljima lamele 'A' kao i ostalih objekata koji se temelje na ovom nivou iskopa, 'C5', delimično 'C4-1' i 'C4-2'. Potom se nakon izrade vertikalnih elemenata ovih objekata kreće sa radovima na osiguranju temeljnih jama za objekte koji se temelje na etaži niže '-3', prevashodno objekti za smeštajni kapacitet, lamela 'B' i 'Vezni deo A-B'.

Osiguranje temeljnih jama se vrši podgradama i zahtevalo bi za ovaj vid terena i složenost kompleksa veoma detaljan plan i razradu kako bi se svi procesi rada uskladili a bezbednost radnika zadovoljila stroge kriterijume. Stepen podgrađivanja za ovu varijantu je najzahtevniji, sa obzirom da bi se prvo radile podgrade za suterensku etažu '-3' a potom nakon izrade temelja i vertikalnih elemenata ove etaže pristupilo bi se osiguranju temeljne jame najniže etaže '-4' - objekti 'C1' i 'C2'.

U odnosu na varijantu 1 gde je bilo problema sa iskopom zbog padavina i klizista ovde to ne bi bio slučaj s obzirom da gradnja kreće odmah, temeljenje prati iskop.

Uslov da kompletna $\mathrm{AB}$ konstrukcija bazenskog dela bude gotova do sredine novembra 2018. godine prekoračena je za preko dvadeset dana (završetak 08.12.2018. godine) što nije malo prekoračenje posebno ukoliko bi došlo do nekih dodatnih odstupanja u realnim uslovima gradnje na terenu.

Kako su završni radovi najzahtevniji na hotelskim krilima, ovom varijantom bi se oni prioritetizovali na ovim delovima a samim tim bi se rokovi za završetak skratili. Međutim, ovo podrazumeva i da su pozicije rada otvorene za veliki broj izvršilaca odjednom. Ovakav potencijal bi se maksimalno mogao iskoristiti jedino $u$ slučaju da ne postoji manjak izvršilaca za ove grupe radova. 


\subsection{Varijantno rešenje 3}

Početak analiziranih aktivnosti 04.06.2018. godine; završetak 23.03.2019. godine.

Ovim varijantnim rešenjem se postiže izrada svih objekata -3 suterenskog nivoa odjednom, lamela 'B', 'Vezni deo A-B', 'C4-1', 'C4-2', 'C3'. Otvara se front rada na više mesta jer objekti na ovom nivou nisu svi jedan uz drugi.

Kreće se sa izradom hotelskih krila kao prioritetnim takođe kao u varijanti 2 , s obzirom na mali produžetak iskopa za lamelu 'B' koja na -3 nivou ima prioritet, ali se postiže to da nema podgrada za ovaj nivo što umnogome smanjuje potencijalne probleme i rizike koje donosi osiguranje temeljnih jama i uklanja vreme potrebno za njihovo izvođenje.

Bazenski delovi se ostavljaju za kraj, kao najmanje prioritetni u ovom slučaju, ali se i pored toga kompletni radovi na $\mathrm{AB}$ konstrukciji završavaju do 01.12.2018. godine što je dve nedelje produžetka roka od zahtevanog ali je u granicama razumnog i svakako bi se planovi za montažu inoksnih bazena za toliki period mogli produžiti, a ova pozicija svakako nije na kritičnom putu u pogledu generalne dinamike za ceo kompleks jer ne sadrži veliki broj etaža poput smeštajnih krila.

Potreba za osiguranjem temeljnih jama nije velika kao u varijanti 2 (osiguranje samo suterenskog nivoa -4 , što $u$ suštini polovi radove vezane za ovu poziciju), dok je u odnosu na varijantu 4 i dalje značajno veća.

Kao i u varijanti 2 ovim pristupom gradnji otvara se prostor za angažman velikog broja izvršilaca na završnim radovima odjednom, s tim da za razliku od varijante 2 postoje otvorene pozicije i za radove na ostalim objektima -3 nivoa što bi moglo biti jako značajno ukoliko postoji dovoljno radne snage da se rasterete frontovi rada $\mathrm{za}$ objekte koji kasnije dođu na red npr. 'C2' i 'C1'.

\subsection{Varijantno rešenje 4}

Početak analiziranih aktivnosti 04.06.2018. godine; završetak 08.06.2019. godine.

Kao i u varijanti 3, nakon iskopa do nivoa -3 kreće se prvo sa izradom lamele 'B' i 'Veznog dela' - drugog smeštajnog krila kao prioritetnog, a potom se prelazi na nivo -4 .

Ostali objekti koji se temelje na ovom nivou se trenutno zanemaruju kao neprioritetni 'C3', 'C4-1' i 'C4-2'. Razlika u odnosu na varijantu 3 je to što se umesto prebacivanjem prioriteta na izradu hotelskog krila lamela 'A' prioritet stavlja na izradu bazenskih objekata.

Ovim varijantnim rešenjem se postiže kompromis $u$ smislu zahteva investitora da se što pre krene sa izradom hotelskih krila (delimično - lamela 'B') kao i bazenskih objekata.

Završetak radova na $\mathrm{AB}$ konstrukciji bazenskog dela planiran za 24.11.2018. godine odstupa samo 9 dana od zadatog roka što ne bi trebao biti problem u blagom odlaganju radova na izradi bazenske tehnike.

Ovakva izgradnja takođe uključuje osiguranje temeljnih jama suterenske etaže -4 podgradama ali to samo za objekte 'C1' i 'C2' čime su radovi na ovom delu u velikoj meri rasterećeniji od varijanti 2 i 3 .
Varijanta 4 je sa stanovišta završnih radova najpogodnija za organizaciju i planiranje, najveći je razmak u izradi lamela 'A' i 'B' koje su najzahtevnije u ovom pogledu, čime se dobija prostor za bolju organizaciju radova kao i manipulacija manjeg broja izvršilaca ukoliko je to neizbežan slučaj.

\subsection{Komparacija varijanti i ocena pouzdanosti rešenja}

Varijanta 2 i varijanta 3 su se sa svojih 286 i 293 kalendarskih dana pokazale kao varijante sa najkraćim rokom za završetak objekta. Upoređujući obe, varijanta 3 deluje kao pogodnije rešenje od varijante 2 sa stanovišta roka završetka svih temelja, završetka $\mathrm{AB}$ radova na bazenskom delu, otvorenošću pozicija za završne radove u startu, kao i iz pogleda obezbeđenja temeljnih jama gde je u ovoj varijanti u odnosu na varijantu 2 prepolovljena potreba za podgrađivanjem. U ostalim karakteristikama su prilično izjednačene ali je u skladu sa prethodno rečenim jasna superiornost varijante 3 .

Sa stanovišta otvaranja bazenskih objekata kao prioritetnih, varijanta 1 jedina poštuje početni zadati rok, mada i varijante 3 i 4 ne odstupaju drastično.

Uzimajući u obzir završavanje temelja u što skorijem roku zbog potencijalnih odrona, lošeg vremena, zimskog perioda, varijanta 3 je neprikosnoveno najpogodnija jer je vremenska razlika u odnosu na završetak temelja sledeće najkraće varijante u ovom pogledu više od dva meseca.

Varijanta 4 iako najdužeg roka izvođenja ima prednost $\mathrm{u}$ odnosu na ostale jer predstavlja kompromis između zahteva za izradu barem jednog hotelskog krila kao i bazenskog dela. Ova varijanta je takođe i najracionalnije strukture u pogledu završnih radova jer je najduži razmak između izgradnje dva hotelska krila koja zahtevaju angažman velikog broja izvršilaca na završnim radovima.

Varijanta 1 koja predstavlja standardan princip izgradnje 'od dole ka gore', nakon kompletnog iskopa koji su zahtevali uslovi predmetnog objekta i terena, ima svoje prednosti u smislu izbegavanja podgrada a samim tim i većeg nivoa bezbednosti na radu. Uz to, ona je i najracionalnija sa finansijske strane. Iako je prvobitno zadovoljila rokove tokom planiranja, mada su bili strogo fiksni bez previše prostora za odstupanja, pokazala se $u$ praksi kao pogrešna u smislu poštovanja roka jer je uz vremenske uslove koji su bili izrazito nepovoljni ostavila i 'gole' iskope dugo vremena pa je to uz ostale faktore napravilo dosta problema zbog pojave odrona i klizišta.

Od svih faktora koji utiču na pouzdanost u izboru optimalnog rešenja, za ovaj rad je izrazito značajan faktor građevinske mehanizacije, jer kompleks sadrži četiri suterenske etaže a dilatirani objekti koji čine celinu su temeljeni na različitim nivoima. $\mathrm{S}$ toga se kao kriterijum $\mathrm{u}$ primeni metode višekriterijumske optimizacije $u$ iznalaženju optimalnog rešenja našla i ocena pouzdanosti mehanizacije za varijantna rešenja (ocene u opsegu od 1 do 5; 1 - najbolja ocena).

Poduhvat iskopa za kompleks bio je izuzetno zahtevan. Iskop preko $70.000 \mathrm{~m} 3$ zemlje u planinskom predelu na kosini nosio je sa sobom veliki rizik od pojave klizišta, kao i nepristupačnih gradilišnih prilaza za transportne mašine zbog potencijalnog zaglavljivanja, proklizavanja, 
prevrtanja i dr. Sastav tla je veoma nepogodan jer je glinovit pa uslet kiša sporo se suši i lepi za gume čime sprečava kretanje mašina na pneumatike.

Rešenjem predstavljenim u varijanti 1 iskopu celokupne površine pod kompleksom se pristupa odjednom, gde je u startu potreban veliki broj mašina, njihovo kvalitetno koordinisanje i praćenje radova. U ovakvom scenariju, kada izgradnja počinje od najniže etaže, od izuzetne je važnosti što pre doći do nivoa od kog se prvo temelji zbog poštovanja rokova. Svaka nepredviđena okolnost drastično može da utiče na produžetak roka, kao što se pokazalo, jer pri lošim vremenskim uslovima a pri otvorenoj celoj površini za iskop stopira se ceo proces rada jer vrsta tla i postavka terena ne dozvoljavaju dalji rad dok se dobro ne osuši tlo, tako da staju sve aktivnosti. Iz ovog ugla, daleko su povoljnije varijante 2 i 3 gde se prvobitni iskop vrši samo do nivoa -2 i -3 a nakon toga se nastavlja sa radovima na iskopu kada se završe zidovi prvih nivoa.

U ovom slučaju i ako dođe do stopiranja radova na daljim iskopima otvorene su pozicije rada na drugim frontovima. Za razliku od varijante 1 gde nema potrebe za podgradama, u ostalim varijantama je iz tog razloga i mehanizacija proširena, što podrazumeva veći broj mašina, njihovih kombinacija kao i veći stepen zahtevnosti radova, ali se ne pristupa radu odjednom nego u fazama tako da je delimično rasterećen iskop, što u dalekoj meri olakšava organizaciju.

Varijanta 4 uz varijantu 1 najmanje je pogodna sa stanovišta pouzdanosti mašina jer podrazumeva proces iskopa koji je u skoro istoj meri intenzivan od starta, pored toga ima potrebu i za izradom podgrada a samim tim i uvođenja dodatnih kombinacija mehanizacije za nivo -4 , mada daleko manje od varijanti 2 i 3 .

\section{METODE I IZBOR OPTIMALNOG REŠENJA}

Izbor optimalnog varijantnog rešenja za pristup građenju predmetnog kompleksa je analiziran metodama višekriterijumske optimizacije: metoda kompromisnog programiranja i metoda višekriterijumskog kompromisnog rangiranja alternativnih rešenja, razmatrajući relevantnu značajnost kriterijuma uvođenjem težinskih koeficijenata.

Težinski koeficijenti analizirani su kroz četiri iteracije gde je svakom od kriterijuma dodeljena dominantna pozicija $u$ odnosu na druge.

U analizi učestvuju četiri kriterijuma od kojih su tri vremenska a četvrti predstavlja ocenu pouzdanosti mehanizacije kao bitan faktor zbog obimnosti radova na iskopu.

f1 - Ukupno vreme za izvođenje kompleksa (dan);

f2 - Ukupno vreme završetka bazenskog dela (dan);

f3 - Ukupno vreme završetka svih temelja (dan);

f4 - Pouzdanost mehanizacije (ocena).

Tabela 1. Ulazni podaci za optimizaciju

\begin{tabular}{|c|c|c|c|c|}
\hline krit. f. / alter. & A1 & A2 & A3 & A4 \\
\hline f1 & 356 & 286 & 293 & 370 \\
\hline f2 & 160 & 188 & 181 & 174 \\
\hline f3 & 160 & 93 & 97 & 174 \\
\hline f4 & 5 & 3 & 2 & 4 \\
\hline
\end{tabular}

$\mathrm{Na}$ osnovu rezultata proračuna metodama višekriterijumske optimizacije može se zaključiti da je najpovoljnije (optimalno) rešenje varijanta 3 , bez obzira na nivo važnosti kriterijuma postignutog preko dodeljenih težinskih koeficijenata.

Tabela 2. Pregledno rangirana rešenja po varijacijama težinskih koeficijenata

\begin{tabular}{|c|c|c|c|c|c|c|c|c|c|c|c|c|c|c|c|c|}
\hline \multirow{2}{*}{\begin{tabular}{|l|}
$\begin{array}{l}\text { Iteracija br. } \\
\text { (redosled rešenja) }\end{array}$ \\
alternativno reš enje: \\
\end{tabular}} & \multicolumn{4}{|c|}{ Iteracija 1} & \multicolumn{4}{|c|}{ Iteracija 2} & \multicolumn{4}{|c|}{ Iteracija 3} & \multicolumn{4}{|c|}{ Iteracija 4} \\
\hline & A1 & A2 & A3 & A4 & A1 & A2 & A3 & A4 & A1 & A2 & A3 & A4 & A1 & A2 & A3 & A \\
\hline$v=0$ & 3 & 2 & 1 & 4 & 4 & 2 & 1 & 3 & 3 & 2 & 1 & 4 & 4 & 2 & 1 & 3 \\
\hline $\mathrm{v}=0.3$ & 3 & 2 & 1 & 4 & 4 & 2 & 1 & 3 & 3 & 2 & 1 & 4 & 4 & 2 & 1 & 3 \\
\hline$v=0.6$ & 3 & 2 & 1 & 4 & 4 & 2 & 1 & 3 & 3 & 2 & 1 & 4 & 4 & 2 & 1 & 3 \\
\hline $\mathrm{v}=0.9$ & 3 & 2 & 1 & 4 & 4 & 2 & 1 & 3 & 3 & 2 & 1 & 4 & 4 & 2 & 1 & 3 \\
\hline $\mathrm{v}=1.0$ & 3 & 2 & 1 & 4 & 3 & 2 & 1 & 4 & 3 & 2 & 1 & 4 & 3 & 2 & 1 & 4 \\
\hline
\end{tabular}

\section{ZAKLJUČAK}

$\mathrm{Na}$ osnovu prethodno iznetog, svaka od varijanti ima svoje prednosti i mane. Klasično rešenje predstavljeno u varijanti 1, koje je bilo predviđeno i projektom, pokazalo se u realnosti kao pogrešno, što je ukazalo da se nije dovoljno truda posvetilo samom razmatranju potencijalnih načina izgradnje, mada su i geomehanička istraživanja podbacila u svojim nalazima i oceni.

Prema svim ključnim stavkama koje su prikazane ovim radom varijanta 3 se pokazala kao najpovoljnije rešenje $u$ generalnoj situaciji na terenu jer je sa stanovišta pouzdanosti mehanizacije najpogodnija, uz to daje prioritet na izradu hotelskih krila za koje i jeste potrebno najviše vremena za izradu, na kritičnom su putu, a ukoliko bi i došlo do odlaganja radova na bazenskom delu bila bi to manja šteta jer ovi radovi nisu kritični u pogledu završetka do otvaranja hotelskog kompleksa. Primenom metode višekriterijumskog kompromisnog rangiranja alternativnih rešenja pokazalo se da bez obzira na način zadavanja težinskih koeficijenata pojedinim kriterijumima varijanta 3 je zaista i optimalna.

\section{LITERATURA}

1. Trivunić, M., Matijević, Z.: „, Tehnologija i organizacija građenja“- praktikum, Fakultet

Tehničkih Nauka, Novi Sad, 2009.

2. Trivunić M., Dražić J., Matijević Z.: „Modeliranje procesa građenja“, FTN Institut za građevinarstvo, Novi Sad 2005.

3. Trbojević, B.: „Organizacija građevinskih radova“, Naučna knjiga, Beograd, 1991

4. Opricović, S.: „Optimizacija sistema“, Građevinski fakultet, Beograd 1992.

5. Opricović, S.: „Višekriterijumska optimizacija sistema u građevinarstvu“, Građevinski fakultet, Beograd 1998.

\section{Kratka biografija:}

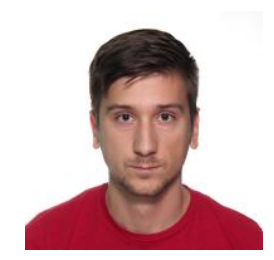

Srđan Ninković rođen je u Šapcu 1990. god. Master rad na Fakultetu tehničkih nauka iz oblasti Građevinarstva Organizacija i tehnologija građenja odbranio je 2021.god. 